\title{
Cavity Sound Pressure Enhancement of the Second Generation Power Generating Helmholtz Resonator with X-shaped Cavity Junction
}

\author{
Iwan Yahya \\ The Iwany Acoustics Research Group (iARG), Physics Dept, Sebelas Maret University, Jl. Ir. Sutami 36A \\ Surakarta, Indonesia, Correspondings-mail: iwanyy@yahoo.com \\ Harjana \\ The Iwany Acoustics Research Group (iARG), Physics Dept, Sebelas Maret University, Jl. Ir. Sutami 36A \\ Surakarta, Indonesia \\ Eki Muqowi \\ The Iwany Acoustics Research Group (iARG), Physics Dept, Sebelas Maret University,Jl. Ir. Sutami 36A \\ Surakrta, Indonesia
}

\begin{abstract}
Cavity sound pressure level is a very important measure when dealing with the design of resonator based power generating sound absorbers and sound diffusers. This paper presents results from experimental study of the performance of the second generation iARG-X2 power generating Helmholtz resonator. The use of specific Xshaped extention for the cavity junction could encrease the sound pressure inside the cavity up to $16 \mathrm{~dB}$ above of the similar resonator without extention. The experiment was conducted with various types sound source, i.e. single tone, dual sine, and random noise that all resulting similar cavity sound pressure increment pattern. It brings new possibility for the development of power generating sound absorber and sound diffuser which is very usefull in green modern life style both for indoor and outdoor noise control applications.
\end{abstract}

Keywords: cavity sound pressure, $\mathrm{x}$-shaped junction, Helmholtz resonator

\section{Introduction}

Currently advances on smart and functional material innovations meet the needs for possibility to create sound and vibration driven power generator in smaller and compact size. Since then sound and vibration based energy harvesting system now facing very promising development not only because of the healthy and green leaving reason but due to its business prospectives either.

Some successive development achieved on nanogenator and piezoelectronic nano wire research has introduce the idea of nanopiezotronic for harvesting energy by using nano scale piezoelectric materials. ${ }^{[1-6]}$ It gives new possibility for improving performance of some acoustics resonator based energy harvesting system. ${ }^{[7]}$

Sound and vibration based energy harvesting system has been widely investigated and developed by many researchers in various way. The use of piezoelectric and its combination with electromagnetic transducer was the most common to convert vibration energy into electricity. ${ }^{[8-11]}$ In other side, the sound driven energy harvesting are very rare and limited yet.

To do the sound driven energy harvesting by using acoustic resonator, researchers utilized the sound wave pressure fluctuation inside the cavity to deflect piezoelectric layer. ${ }^{[12-15]}$ So to increase sound pressure level inside resonator cavity indeed one of very challenging work in the development of sound driven energy harvesting technology.

This paper presenting result from laboratory investigation on the use of $\mathrm{x}$-shaped cavity junction for increasing the pressure of the sound wave inside Helmholtz resonator cavity.

\section{The X-shaped Cavity Junction Resonator}

Enhancement of acoustic energy harvesting has been done i.e. by Carrara et by using elliptical acoustic mirror configuration. Acoustic harvester was formed along a semi elliptical path on the surface of a plate. ${ }^{[16]}$ Different 
technique was implemented in power generating sound absorber design by placing specific shaped extended neck on certain posisition inside of resonator cavity. ${ }^{[17]}$

The $\mathrm{x}$-shaped cavity junction reported in this paper was developed for improving the previous design in Ref (17). It consist of two horn-shaped necks attached to the coupled cavities as depicted in Figure (1).

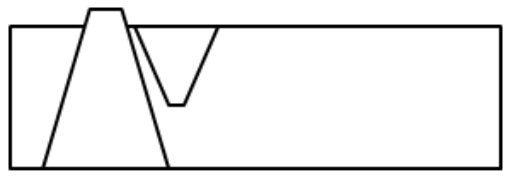

Fig. 1. Basic design of the $\mathrm{x}$-shaped cavity which is work as inter-cavity junction between cavities of Helmholtz resonator.

The two horn-shaped extended neck was placed in opposite direction each other to form $\mathrm{x}$-shaped configuration inside the inter-cavity junction.

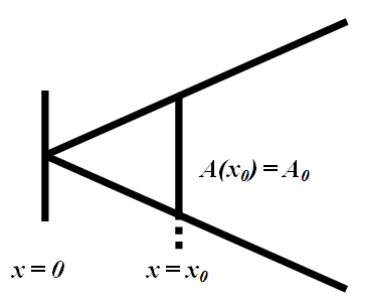

Fig. 2. Mathematical model of the extended neck.

A mathematical model after Kulik ${ }^{[18]}$ was used for derive equation for the wave propagation along the junction as depicted in Figure (2). The upstream and downstream component of the sound wave is given by, $g(x)=p(x) x=g_{\rightarrow} e^{-i k x}+g_{\leftarrow} e^{+i k x}$

According Figure (2), for junction diameter $x \gg \lambda / 2 \pi$ the impedance is

$$
\begin{aligned}
Z(x) & =\frac{p_{\rightarrow(x)}}{v_{\rightarrow(x)}} \\
& =\rho c[(j 2 \pi x / \lambda) /((j 2 \pi x / \lambda)+1)]
\end{aligned}
$$

\section{Method}

The laboratory investigation was conducted by using two similar horn shaped junction with the mouth tip and horn diameter $0.5 \mathrm{~cm}$ and $4.5 \mathrm{~cm}$ respectively.

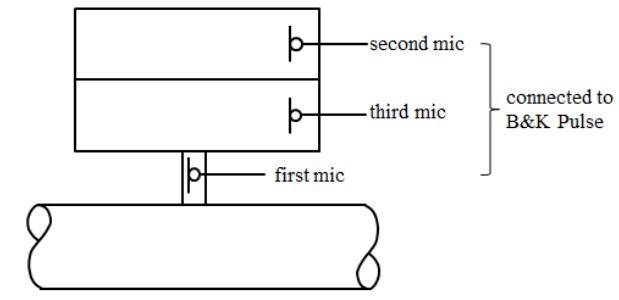

Fig. 3. Experiment configuration using three microphones. The tested Helmholtz resonator attached as a side branch of B\&K 4206 impedance tube.

Tested Helmholtz resonator was attached as side branch of B\&K 4206 impedance tube. All experiments controlled by using B\&K LAN-XI Data Acquisition System in three different sound waves types single tone, dual sine and random noise. Three pieces B\&K 4189 quarter inch microphones used for capturing the each type of sound waves in three different point as ilustrated in Figure (3).

First microphone attached to the Helmholtz resonator neck, while the second and third microphone placed in the second cavity and the inter-cavity junction respectively. All microphones connected to the FFT modul of the B\&K Pulse. The all captured signals then to be analyzed using FFT analyzer to get its FFT spectrum.

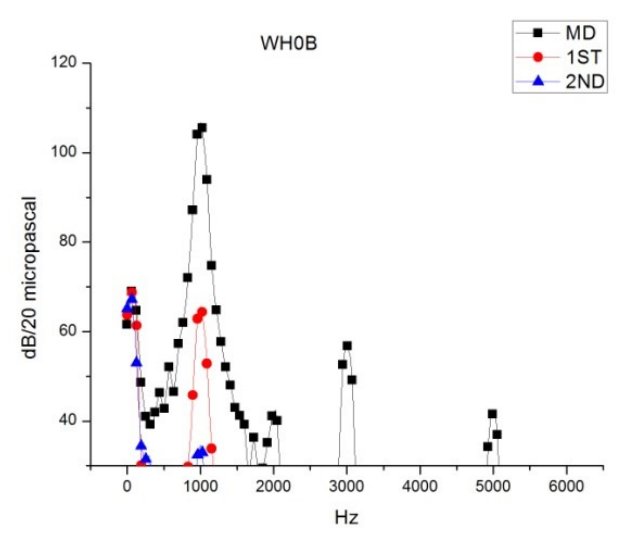

Fig. 4. Measured sound pressure level on the experimen without $\mathrm{x}$-shaped cavity junction.

\section{Result and Discussion}

FFT spectrum resulted from experiment on two cavity Helmholtz resonator without and with $\mathrm{x}$-shaped 
cavity junction depicted in Figure (4) and Figure (5) respictevely. Sound pressure from the main duct in the resonator neck is $105 \mathrm{~dB} / 20 \mu \mathrm{Pa}$, while measured sound pressure level by the second and third microphone are $64 \mathrm{~dB} / 20 \mu \mathrm{Pa}$ and $33 \mathrm{~dB} / 20 \mu \mathrm{Pa}$.

A very significant amplification occured on third microphone when the $\mathrm{x}$-shaped cavity junction attached as shown in Figure (5). Measured sound prsessure level by second and third microphones are $62,6 \mathrm{~dB} / 20 \mu \mathrm{Pa}$ and $49,7 \mathrm{~dB} / 20 \mu \mathrm{Pa}$.

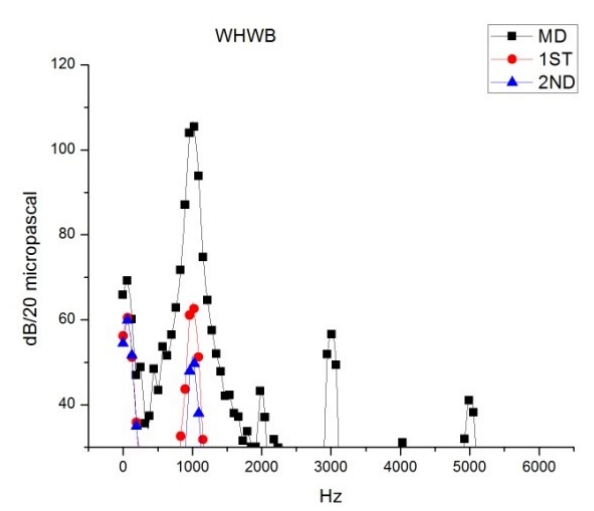

Fig. 5. Measured sound pressure level when the $\mathrm{x}$-shaped cavity junction attached.

Figure (5) shows increament of $16,6 \mathrm{~dB} / 20 \mu \mathrm{Pa}$ on the third microphone when the proposed $\mathrm{x}$-shaped cavity junction attached inside the Helmholtz resonator. Increament of $16,6 \mathrm{~dB}$ is much higher compared to the 3 $\mathrm{dB}$ increament reached on the previous work as reported in Ref (17). Similar sound pressure increament phenomena also occur on the experiment using dual sine sound wave $4 \mathrm{kHz}$ and $6 \mathrm{kHz}$ as shown in Figure (6).

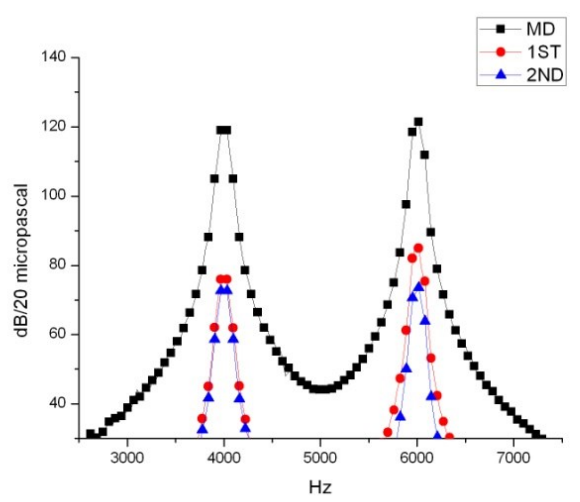

Fig. 6. Result from experiment using dual sine $4 \mathrm{kHz}$ and 6 $\mathrm{kHz}$ sound source.
The inner cavity sound pressure level increament as the $\mathrm{x}$-shaped cavity junction attached to the helmholtz resonator is related to the change of junction impedance. As the junction diameter decrease, the particle velocity decreased but the sound pressure increased exponentially and reach its maximum when flow along short straight thin tube on the reverse horn-shaped tip.

Accordingly, the small decreament of sound pressure level from $64 \mathrm{~dB} / 20 \mu \mathrm{Pa}$ as shown on Figure (4) to $62,6 \mathrm{~dB} / 20 \mu \mathrm{Pa}$ on Figure (5) due to quasi expansion junction on the boundary between first horn to the second horn of the $\mathrm{x}$-shaped cavity junction.

When the sound wave reach the interface of second cavity of the Helmholtz resonator with the top side of the x-cavity junction, the particle velocity and sound presssure changes due to boundary condition. It caused sound pressure level decrease. As the sound wave flows through the second reverse horn the second step of sound pressure level increament occured as shown in Figure (5) and Figure (6).

It shown that proposed $\mathrm{x}$-shaped cavity junction reported in this paper has significant advantages not only on increasing of the Helmholtz resonator inner cavity sound pressure level but on the possibility for focusing the sound wave to arbitrary focal point inside the cavity either.

The higher inner cavity sound pressure level is very important in sound driven energy harvesting system since the higher pressure required for driving higher stress to the piezoelectric layer to get higher electricity output.

The ability of $\mathrm{x}$-shaped cavity junction on focusing the sound wave to arbitrary position brings advantage for increasing driving force to a focal point on the piezoelectric layer which is not yet reported by previous researchers. It also providing felexibility on custom designing Helmholtz resonator based sound driven energy harvesting energy.

\section{Conclusion}

The proposed $\mathrm{x}$-shaped cavity junction reported in this paper has two significant advantages on the ability for icreasing the inner cavity sound pressure level and the possibility for focusing sound waves to arbitrary focal position inside the resonator cavity. It brings possibility for creating custom designing improved Helmholtz resonator based sound driven energy harvesting system. 


\section{Acknowledgements}

The authors would like to thanks the Directorate Generale of Higher Education (DGHE) Republic of Indonesia and the Research Institute (LPPM) of Sebelas Maret University - UNS SOLO for supporting the research through the AUPT Research Grant Contract No. 351/UN27.11/PN/2014. To their colleagues at the Physics Department for the very nice academic atmosphere and sharing, and all students at iARG for the spirit and discussions.

\section{References}

1. Wang, X., Song, J., Liu, J., and Wang, Z. L., Direct current nanogenerator driven by ultrasonic waves. Science 316 (2007) 102-105

2. Wang, Z. L., The new field of nanopiezotronic. Materials Today 10 (5) (2007) 20-28

3. Wang, Z. L., Wang, X., Song, J., Liu, J., and Gao, Y., Piezoelectric nanogenerator for self power nano devices. IEEE Pervasive Computing 7(1) (2008) 49-55

4. Wang, Z. L., Energy harvesting using piezoelectric nanowire - A correspondent on Energy Harvesting Nanowires? By Alexe et al. Advance Materials 21 (2009) 1311-1315

5. Hu, Y., Zhang, Y., Xu, C., Zhu, G., and Wang, Z. L., High output nanogenerator by rational unipolar assembly of conical nanowire and its applications for driving a small liquid crystal display. Nano Letter (2010) (DOI: 10.1021/n1103203u)

6. Wang, Z. L., Piezotronic and piezophototronic effect. Journal of Physical Chemistry Letters 1 (2010) 13881393

7. Cha, S. N., Seo, J. S., Kim, S. M., Kim, H. J., Park, Y. J., Kim, S. W., and Kim J. M., Sound-driven piezoelectric nanowire-base nanogenerators. Advanced Materials 22 (2010) 4726-4730

8. Andosca, R., McDonald T. G., Genova, V., Rosenberg, S., Keating, J., Benedixen, C., and Wu, J., Experimental and theoretical studies on MEMS piezoelectric vibrational energy harvester with mass loading., Sensor and Actuator A: Physical 178 (2012) 76-87

9. Tang, X., and Zuo, L., Enhanced vibration energy harvesting using dual-mass system. Journal of Sound and Vibration 330 (2011) 5199-5209

10. Harne, R., L., Theoretical investigation of energy harvesting efficiency from structural vibrations using piezoelectric and electromagnetic oscillator. J. Acoust. Soc. Am. 132 (1) (2012) 162-172

11. Gonzales, C. G., Franco, V. R., Brennan, M. J., da Silva, S., and Junior, V. L., Energy harvesting using piezoelectric and electromagnetic transducers. Proceedings of 9th Brazilian Conference on Dynamics
Control and their Applications. (Serra Negra, 2010) pp 1166-1171

12. Liu, F., Horowitz, S. B., Nishida, T., Cattafesta, L., and Sheplak, M., A multiple degree of freedom electromechanical Helmholtz resonator. J. Acoust. Soc Am. 122 (1) (2007) 291-301

13. Horowitz, S. B., Sheplak, M., Cattafesta, L., and Nishida, T., MEMS acoustic energy harvester. Proceedings of Power MEMS (Tokyo, Japan, 2005) pp 13-16

14. Li, B., and You, J. H., Harvesting ambient acoustic energy using acoustic resonator. Proceeding 161st Meeting of Acoustical Society of America (Seatle, Washington, USA, 2011) pp 1-8

15. Li, B., You, J. H., Laviage, A. J., and Kim, Y. J., Acoustic energy harvesting using quarter wavelength straight-tube resonator. Proceedings of IMECE201286989 (Houton, Texas, USA, 2012) pp 1-7

16. Carrara, M., Cacan, M. R., Leamy, M. J., Ruzzene, M., and Eturk, A., Dramatic enhancement of structure-borne wave energy harvesting using an elliptical acoustic mirror. Applied Physics Letter 100, 204105 (2012) 1-4

17. Yahya, I. iARG advance in power generating sound absorber. Proceedings of AGCM (Solo, Indonesia, 2011) pp 1-3

18. Kulik, Y., Transfer Matrix of Conical Waveguides with any Geometric Parameters for Increased Precision in Computer Modeling. J. Acoust. Soc. Am 122 (5) (2007) 179-184. 